\title{
Association between social phobia and the risk of arrhythmia using the Korean National Sample Cohort: a retrospective cohort study
}

\author{
Hyunkyu Kim 1,2,3, , Wonjeong Jeong 2,5, Seung Hoon Kim 1,2, Jun Ho Seo 3,4 , Jin Sun Ryu 3,4 , You-seok Kim 2,6, \\ Jeong-Ho Seok ${ }^{3,4}$, Sung-In Jang ${ }^{1,2}$ and Eun-Cheol Park ${ }^{1,2^{*}}$
}

\begin{abstract}
Background: Social phobia shares symptoms with arrhythmias, such as palpitations and chest discomfort. However, it is unclear how social phobia is associated with the actual risk of arrhythmia. This study aimed to investigate whether social phobia is associated with the risk of arrhythmia using a nationally representative sample cohort.

Methods: This retrospective cohort study assessed data from the 2002-2013 Korean National Health Insurance Service National Sample Cohort. Using 1:3 propensity score matching for sex, age, income, and insurance status, 1514 patients with social phobia and 4542 control group patients were included in the study. Social phobia and arrhythmia were defined per the International Classification of Diseases, 10th revision. Using cox proportional hazard regression, hazard ratios (HRs) were calculated to estimate the risk of arrhythmia in patients with social phobia.

Results: There were statistically significant associations between social phobia history and elevated risks of arrhythmia. Patients with social phobia had a higher risk of arrhythmia after adjusting with covariates $(H R=1.78$, $95 \% \mathrm{Cl}=1.25-2.55)$. Among different types of arrhythmias, atrial fibrillation and flutter presented the highest risk $(\mathrm{HR}=2.20, \mathrm{Cl}=1.06-4.57)$ compared to paroxysmal tachycardia $(\mathrm{HR}=1.07, \mathrm{Cl}=0.39-2.91)$ and other cardiac arrhythmias $(\mathrm{HR}=1.83, \mathrm{Cl}=1.16-2.89)$.

Conclusion: This study identified the association between social phobia and the risk of arrhythmia in a South Korean representative cohort. These results suggest that social phobia should be treated properly to reduce arrhythmia risks.
\end{abstract}

Keywords: Social phobia, Arrhythmia, Retrospective cohort study, Propensity score matching

\section{Background}

Psychiatric disorders and psychological conditions have been associated with the occurrence of physical illness [1-4]. It is well-proven that physical diseases, such as strokes, Parkinson's disease, and heart diseases, cause

\footnotetext{
*Correspondence: ecpark@yuhs.ac

1 Department of Preventive Medicine \& Institute of Health Services

Research, Yonsei University College of Medicine, 50 Yonsei-ro,

Seodaemun-gu, Seoul 03722, Republic of Korea

Full list of author information is available at the end of the article
}

psychiatric symptoms such as depression, anxiety, or sleep disturbance [5-7]. Conversely, the hypothesis that mental illness causes physical illness has also been investigated. Particularly, hypotheses have posited that anxiety disorders can cause physical symptoms, such as palpitations, chest pain, and difficulty in breathing, and studies continue to examine these relationships $[8,9]$. Previous research has shown that generalized anxiety and panic disorders are associated with risks of coronary heart disease and other cardiovascular diseases [10-12]. These 
studies suggest that further associations between other types of anxiety disorders and physical illnesses might exist.

Among various anxiety disorders, social anxiety disorder or social phobia is one of the most common and distressing conditions, wherein a person feels severe anxiety and associated physical symptoms in social situations $[13,14]$. Cultural contexts affect the prevalence of this disease; yet, its lifetime prevalence is considered to be higher than 10\% [15-17]. However, since these symptoms occur in specific social situations, many patients simply avoid the same and rarely utilize mental health management or treatment services [18]. Nevertheless, simply avoiding situations to eliminate experiencing psychological and physiological symptoms does not cure social phobias, for which continuous cognitive behavior therapy, psychotherapy, and medication are required. Among physiological symptoms, many patients with social anxiety disorder have reported experiencing palpitations that feel like arrhythmia. However, studies have not yet determined whether social anxiety disorder causes arrhythmia, necessitating investigation and validation of the same through large-scale cohort studies. Relevant results could serve as the basis for improving treatments for both arrhythmia and social anxiety disorder.

This study aimed to investigate the association between social phobia and risk of arrhythmias, as well as the differences among various types of arrhythmia among patients with social phobia, using Korean nationwide claims data.

\section{Methods}

\section{Study population and data}

The data analyzed in this study were acquired from the Korean National Health Insurance Service National Sample Cohort (NHIS-NSC) of 2002 and 2013, from the National Health Insurance Service (NHIS). The Korean NHIS provides researchers with all data of claims collected under the NHIS for academic investigation and policymaking. Since universal healthcare coverage was achieved in 1989, the Korean NHIS has been collecting all claims data from all cases of South Korean medical utilization. Among the 47,851,928 individuals in 2002, $46,605,433$ individuals were selected after excluding noncitizens, for constructing the sample cohort. From the full NHIS database, the representative sample cohort was constructed with 1,025,340 individuals, comprising $2.2 \%$ of the total South Korean population by random stratification [19]. Participants from the cohort were followed up with and all visiting data were recorded in a database; those who passed away or migrated were excluded. Moreover, those who had sought treatment for social phobias or arrhythmia within a year of the washout period were also excluded, as were individuals diagnosed with arrhythmia within a year of social phobia diagnoses. After exclusion, 1514 individuals were selected as the social phobia group.

The NHIS-NSC database includes information on socioeconomic status and codes from the clinically determined International Classification of Diseases, 10th revision (ICD-10). Since we used the de-identified these data, the need for informed consent was waived by the Institutional Review Board of Yonsei University's Health System (4-2021-0155).

Participants of the social phobia group were then matched with control group participants (who had not been previously diagnosed with social phobia or arrhythmia) via propensity score matching. The propensity score was derived using logistic regression to calculate the probability of social phobia with covariates of sex, age, insurance, and income status. After calculating the propensity score, 1:3 greedy matching was performed using the OneToManyMTCH macro for SAS [20].

\section{Study variables and covariates}

The classification of social phobia was based on the diagnostic ICD-10 codes F40.1. Participants' first dates of diagnosis with $\mathrm{F} 40.1$ by doctors were regarded as the diagnoses dates for social phobia. Participants with ICD-10 codes I47, I48, and I49 were considered to have arrhythmias. For each participant, we identified the date of diagnosis of arrhythmia or the end of the study period (December 30, 2013) as the final follow-up date. Various demographic variables that might affect the occurrence of social phobia or arrhythmia, such as age, sex, social security status, residential region, disability, income status, and the Charlson comorbidity index (CCI), were included in the regression model as covariates. CCI score is the index for assessing the participants' comorbidities which can alter the risk of mortality for use in longitudinal studies. The score was calculated by weighting $1 \sim 6$ scores for 19 comorbid diseases. The comorbid disease categories included in CCI score consists of myocardial, vascular, pulmonary, endocrine renal, gastrointestinal, cancer/immune and neurologic comorbid diseases [21]. Dementia is the only psychiatric comorbid disease included in the CCI evaluation and categorized into neurologic comorbid disease. We used the ICD-10 codes for each comorbid disease to calculate the CCI score of participants [22].. Participants were divided into three groups according to their CCI scores: $0-2,3-4, \geq 5$. The diagnoses of diabetes, hypertension, chronic obstructive pulmonary disease (COPD) and hyperthyroidism obtained by using ICD-10 codes were also included in the analysis. Age was divided into seven 10-year groups (0-9, $10-19,20-29,30-39,40-49,50-59, \geq 60$ ) to distinguish 
between risks of arrhythmias among age groups. Region was divided into three categories according to population density: metropolitan, city, and rural. Social security status was categorized by participants' health insurance status as per the criteria of South Korea's National Health Insurance system within which self-employed or privately employed individuals are covered by National Health Insurance. Medical aid beneficiaries consist of individuals who have an income below the government-defined poverty threshold, or disabilities which enable them to receive free inpatient and outpatient care through the government. For the dependent variable subgroup analysis, arrhythmias were sub-grouped into three different categories: paroxysmal tachycardia (I47), atrial fibrillation/flutter (I48), and other cardiac arrhythmias (I49).

\section{Statistical analysis}

We first examined the frequencies and percentages of each categorical variable at each participant's baseline, and performed chi squared tests to examine the distribution of arrhythmias according to each variable. Consequently, a Cox proportional hazards model was generated for examining the association between social phobia and the risk of arrhythmia. All Cox proportional hazard models were fully adjusted with the covariates presented in Table 1. We divided participants with arrhythmia into three groups by their ICD-10 codes, and included as the outcome variables comparing to patients without arrhythmia in Cox model to investigate the risk of each type of arrhythmia. Social phobia history as exposure variable and all other covariates and were included in the analysis. Kaplan-Meier survival curves were used to compare survival rates among the groups. The results were presented as hazard ratios (HRs) with 95\% confidence intervals (95\% CIs) to compare the risk of arrhythmia. All analyses were conducted using the SAS software version 9.4 (SAS Institute, Cary, North Carolina, USA), and $\mathrm{R}$ version 4.0.3. Statistical significance was determined by a two-tailed test with a $p$ value of 0.05 as the threshold.

\section{Results}

The sample's baseline characteristics are presented in Table 1. A total of 6056 participants were included in the analysis, with $3.1 \%$ of them diagnosed with arrhythmia. The chi-squared test showed no statistical difference in the prevalence of arrhythmia between groups divided by the diagnosis of social phobia. Further, gender, social security status, region, disability, and income were also not associated with arrhythmia. Contrastingly, the univariate analyses revealed that age, hypertension, diabetes, and CCI had statistically significant effects on the risk of arrhythmia.
Table 2 shows the results of the survival analysis using the Cox proportional hazards regression model. Unlike results from the univariate analysis, individuals with social phobia had 1.78 times higher risks of arrhythmia after adjusting with covariates $(\mathrm{HR}=1.78$, $95 \% \mathrm{CI}=1.25-2.55)$. Hypertension was also a statistically significant factor affecting the risk of arrhythmia $(\mathrm{HR}=3.50,95 \% \mathrm{CI}=2.46-5.00)$, as was hyperthyroidism $(\mathrm{HR}=1.87,95 \% \mathrm{CI}=1.15-3.04)$. In contrast, gender, social security status, region, disability, diabetes, COPD, and income were not associated with the risk of arrhythmia. The results of the Kaplan-Meier curves for the sample are shown in Fig. 1. Participants with social phobia showed lower survival probability without arrhythmia as compared to those without social phobia.

After subgrouping arrhythmia into three groups by ICD-10 codes, atrial fibrillation and flutter (I47) showed the highest risk of arrhythmia $(H R=2.20,95 \%$ $\mathrm{CI}==1.06-4.57)$ as compared to Paroxysmal tachycardia $(\mathrm{I} 48, \mathrm{HR}=1.07,95 \% \mathrm{CI}=0.39-2.91)$ and other cardiac arrhythmias $(\mathrm{I} 49, \mathrm{HR}=1.83,95 \% \mathrm{CI}=1.16-2.89)$ (Table 3).

\section{Discussion}

This longitudinal study found that diagnoses of social phobia are associated with elevated risks of arrhythmia among a South Korean national sample. Furthermore, among the types of arrhythmias, atrial fibrillation and flutter were most significantly associated with social phobias.

To our knowledge, this study is the first to investigate the association between social phobia and the risk of arrhythmia in a nationwide sample. Few previous studies have attempted to establish the connection between anxiety disorders and arrhythmia, and their results have generally agreed with ours. For instance, a study with a three-year follow-up period suggested that phobic anxiety was associated with ventricular arrhythmias (Odds ratio $=1.40$ ) [23]. Several studies have revealed that anxiety after cardiac intervention or surgery is associated with an elevated risk of arrhythmia [24, 25]. However, no study has investigated the relationship between social phobia and arrhythmia. Only a few studies have examined the relationship between social phobia and other cardiac diseases [26], but their variables were limited to hypertension. The lack of research on phobia is could be due to the underestimation of the disease by patients and clinicians. Patients with social phobia tend to avoid situations that provoke their anxiety symptoms, potentially reducing their intentions to seek proper treatment such as cognitive behavior therapy or medication. Similarly, clinicians and researchers might underestimate social phobia because it is regarded as a less severe condition 
Table 1 Baseline characteristics of the study population and the results of chi-square test with the Social phobia history and risk of arrhythmia

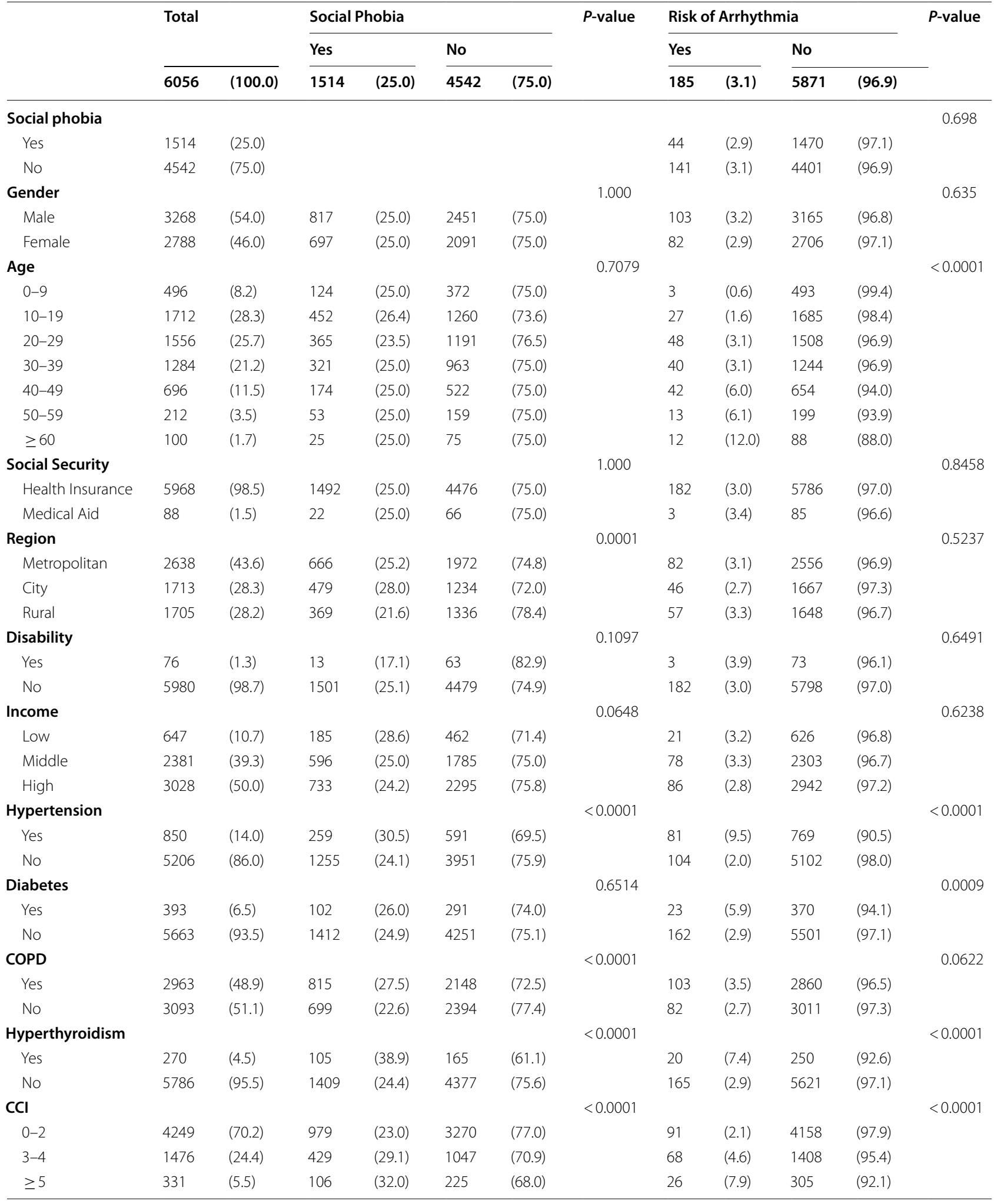

Values are presented as number (\%). COPD Chronic obstructive pulmonary disease, CCI Charlson Comorbidity Index 
Table 2 Results of the Cox Proportional Hazard Regression analysis on the association between social phobia and the risk of Arrhythmia

\begin{tabular}{|c|c|c|c|c|c|}
\hline \multirow[t]{2}{*}{ Variables } & \multicolumn{5}{|c|}{ Risk of Arrhythmia } \\
\hline & HR & $95 \% \mathrm{C}$ & & & $P$-value \\
\hline \multicolumn{6}{|l|}{ Social Phobia } \\
\hline Yes & 1.78 & $(1.25$ & - & $2.55)$ & 0.0016 \\
\hline No & 1.00 & & & & \\
\hline \multicolumn{6}{|l|}{ Gender } \\
\hline Male & 1.00 & & & & \\
\hline Female & 0.91 & $(0.67$ & - & $1.23)$ & 0.5382 \\
\hline \multicolumn{6}{|l|}{ Age } \\
\hline $0-9$ & 0.30 & $(0.09$ & - & $0.97)$ & 0.0440 \\
\hline $10-19$ & 0.65 & $(0.40$ & - & $1.05)$ & 0.0797 \\
\hline $20-29$ & 1.00 & & & & \\
\hline $30-39$ & 0.81 & $(0.53$ & - & 1.24) & 0.3313 \\
\hline $40-49$ & 1.16 & $(0.73$ & - & 1.83) & 0.5380 \\
\hline $50-59$ & 0.87 & $(0.45$ & - & 1.69) & 0.6785 \\
\hline$\geq 60$ & 1.52 & $(0.73$ & - & 3.15) & 0.2624 \\
\hline \multicolumn{6}{|l|}{ Social Security } \\
\hline Health Insurance & 1.00 & & & & \\
\hline Medical Aid & 1.22 & $(0.35$ & - & 4.26) & 0.7526 \\
\hline \multicolumn{6}{|l|}{ Region } \\
\hline Metropolitan & 1.00 & & & & \\
\hline City & 0.82 & $(0.57$ & - & 1.18) & 0.2913 \\
\hline Rural & 0.99 & $(0.70$ & - & 1.39) & 0.9378 \\
\hline \multicolumn{6}{|l|}{ Disability } \\
\hline Yes & 0.73 & $(0.23$ & - & $2.34)$ & 0.5983 \\
\hline No & 1.00 & & & & \\
\hline \multicolumn{6}{|l|}{ Income } \\
\hline Low & 1.00 & & & & \\
\hline Middle & 1.01 & $(0.61$ & - & 1.70) & 0.9574 \\
\hline High & 0.82 & $(0.49$ & - & 1.38) & 0.4517 \\
\hline \multicolumn{6}{|l|}{ Hypertension } \\
\hline Yes & 3.50 & $(2.46$ & - & $5.00)$ & $<0.0001$ \\
\hline No & 1.00 & & & & \\
\hline \multicolumn{6}{|l|}{ Diabetes } \\
\hline Yes & 0.81 & $(0.51$ & - & 1.30) & 0.3852 \\
\hline No & 1.00 & & & & \\
\hline \multicolumn{6}{|l|}{ COPD } \\
\hline Yes & 0.98 & $(0.70$ & - & 1.37) & 0.9081 \\
\hline No & 1.00 & & & & \\
\hline \multicolumn{6}{|l|}{ Hyperthyroidism } \\
\hline Yes & 1.87 & $(1.15$ & - & $3.04)$ & 0.0113 \\
\hline No & 1.00 & & & & \\
\hline \multicolumn{6}{|l|}{$\mathrm{CCl}$} \\
\hline $0-2$ & 1.00 & & & & \\
\hline $3-4$ & 1.54 & $(1.07$ & - & 2.23) & 0.0214 \\
\hline$\geq 5$ & 1.61 & $(0.94$ & - & 2.74) & 0.0805 \\
\hline
\end{tabular}

All variables were included in Cox proportional hazard model. COPD Chronic obstructive pulmonary disease, $\mathrm{HR}$ Hazard ratio, $\mathrm{Cl}$ confidence interval, $\mathrm{CCl}$ Charlson Comorbidity Index as compared to severe depression or bipolar disorders. However, as our results suggest, social phobia might affect serious physiological conditions, including arrhythmia. Thus, proper treatment for patients with social phobia with comprehensive education and applied research should be provided to reduce any relevant complications.

How social anxiety affects the emergence of arrhythmia could not be determined; however, several possible hypotheses exist. The results of our subgroup analysis suggest that social phobia or anxiety are associated with higher risks of arrhythmias. The dependent subgroup analysis showed that atrial fibrillation and flutter had the highest and most statistically significant hazard ratios associated with social phobia history. Atrial fibrillation is more prevalent among older age groups; thus, aging is considered as one of the risk factors for atrial fibrillation [27, 28]. Higher heart rates and overstimulation of the sympathetic nervous system might produce early aging or structural changes of the heart, which can induce atrial fibrillation or other arrhythmias. Moreover, anxiety could alter the autonomic nervous system and induce a different pattern of sympathetic activity which can increase the risk of arrhythmia [29, 30]. Another hypothesis is that patients with anxiety might recognize or detect heart symptoms earlier than others. Thus, their diagnoses of cardiac diseases could be higher than those of individuals without anxiety [31]. Patients with anxiety disorders usually have symptoms of palpitation or chest discomfort; moreover, they tend to visit clinics to test their physical conditions, which might increase the diagnosis rate of arrhythmia among such anxious. Further research should investigate the mechanisms linking social phobia and arrhythmias.

This study has several limitations. First, as we used a retrospective cohort, we could not include all variables that might affect arrhythmia development, such as family history, exercise status, height, weight, and health behaviors including smoking and drinking. Also, all detailed drug history and other disease history that might affect the incidence of arrhythmia were not included in the analysis. Additionally, the confounding variables included in our analyses could have changed throughout the 12-year study period. Thus, we applied the propensity score matching for the study population to reduce the effects of confounding variables. Second, the number of patients diagnosed with social phobia might be underestimated in the analysis. The prevalence of social phobia varied between 1.9 and $20.4 \%$ across different levels of distress [32]. However, less than $0.17 \%$ of the sample had visited clinics during the study period. Patients suffering from social phobia symptoms may be reluctant to receive treatment for psychiatric disorders, as they are often regarded as cultural taboos in Korea. Therefore, 


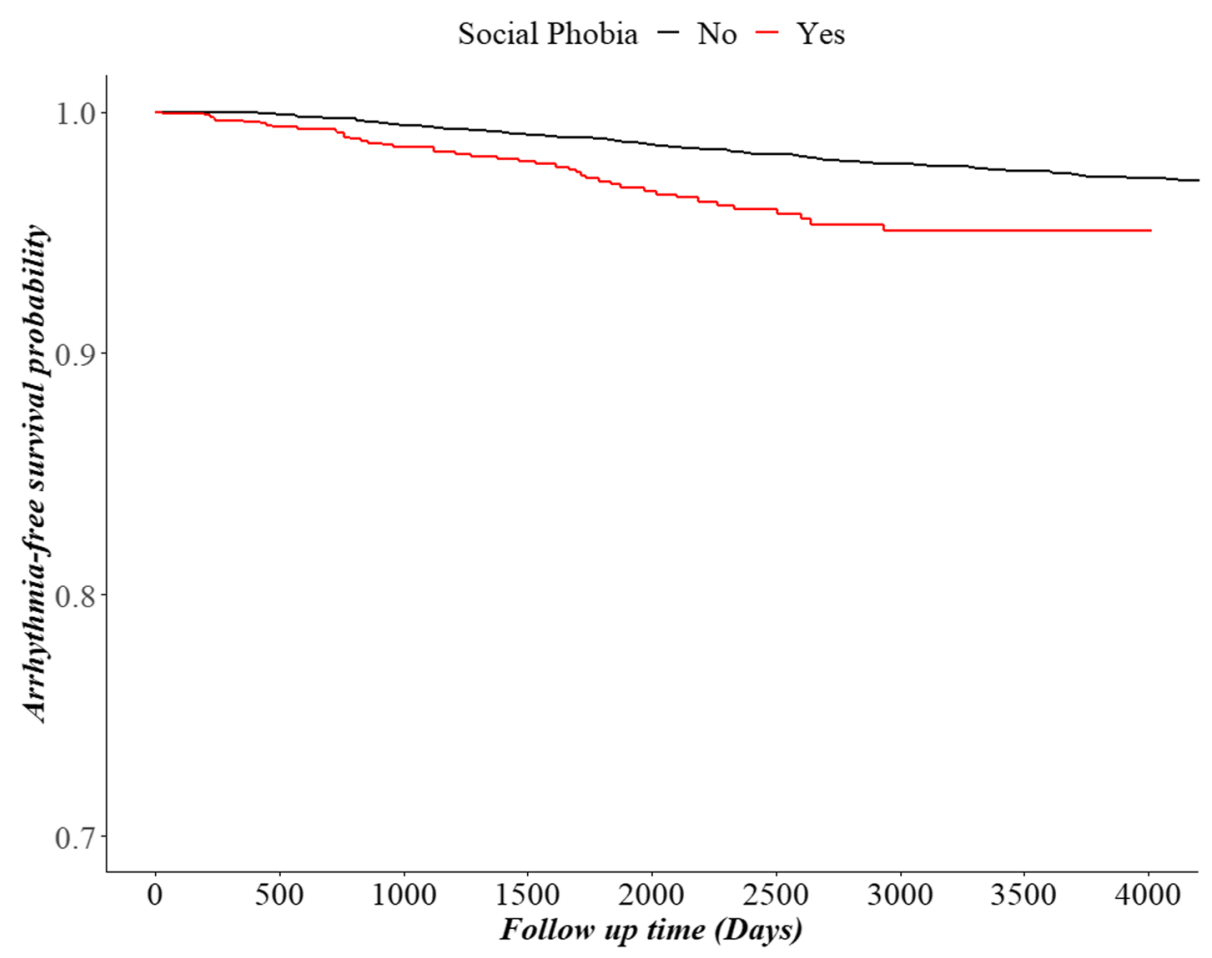

Fig. 1 Kaplan-Meier Curve for the risk of arrhythmia divided by the positive history of social phobia

Table 3 Subgroup analysis of arrhythmia by ICD-10 code and association with social phobia

\begin{tabular}{|c|c|c|c|c|c|c|c|c|c|c|c|c|}
\hline \multirow[b]{3}{*}{ Social Phobia } & \multicolumn{4}{|c|}{ Paroxysmal tachycardia (147) } & \multicolumn{4}{|c|}{ Atrial fibrillation and flutter (148) } & \multicolumn{4}{|c|}{ Other cardiac arrhythmias (149) } \\
\hline & \multirow{2}{*}{$\begin{array}{l}\text { HR } \\
1.07\end{array}$} & \multicolumn{3}{|c|}{$95 \% \mathrm{Cl}$} & \multirow{2}{*}{$\begin{array}{l}\mathbf{H R} \\
2.20\end{array}$} & \multicolumn{3}{|c|}{$95 \% \mathrm{Cl}$} & \multirow{2}{*}{$\begin{array}{l}\mathbf{H R} \\
1.83\end{array}$} & \multicolumn{3}{|c|}{$95 \% \mathrm{Cl}$} \\
\hline & & $(0.39$ & - & 2.91) & & $(1.06$ & - & 4.57) & & $(1.16$ & - & 2.89) \\
\hline
\end{tabular}
Hazard ratio, $\mathrm{Cl}$ Confidence interval

the number of patients with social phobia analyzed could be lower than the actual population with social phobia. Third, the accuracy of diagnostic information may be limited due to the inaccuracy of claims diagnoses, as suggested by a previous study [33]. To enhance diagnosis accuracy, we investigated the primary and secondary diagnostic codes and included both in the analysis. Fourth, we could not evaluate the symptom severity of social anxiety and arrhythmias. As we only defined participants using the ICD-10 codes, we could not assume the severity of the symptoms, and thus, the dose-relationship could not be established. Finally, due to the retrospective nature of the data, causal relationships could not be established. The increased risk of arrhythmia might be a temporal occurrence rather than a causal relationship.

Despite these limitations, our study possesses certain strengths. Although using claims data has its limitations, we used national cohort data, which represented the general population of Korea. The results of our study can be generalized to the entire population of South Korean individuals or other countries with similar demographic characteristics, and provide a background for the management of social phobia to curb risks of arrhythmia. This study also applied propensity score matching to reduce confounding between patients with social phobia and the control group. Moreover, since we only included patients with new-onset social phobia, this study provides additional evidence that new-onset social phobia is a risk factor for arrhythmia.

\section{Conclusion}

In conclusion, this was the first study to identify the relationship between the history of social phobia and the risk of arrhythmia among a South Korean national representative cohort. Individuals diagnosed with social phobia are at 1.84 times higher risk of arrhythmia. Furthermore, 
atrial fibrillation and flutter are most strongly associated with social phobia. While risks presented by social phobia are often underestimated as it is easy to avoid relevant triggering situations, proper treatment may prevent the elevation of arrhythmia risks. Further research using prospective designs to assess the causality of social phobiainduced arrhythmia in a controlled environment should be conducted to validate these findings.

\section{Acknowledgements}

This work was supported by the Korea Medical Device Development Fund grant funded by the Korea government (the Ministry of Science and ICT, the Ministry of Trade, Industry and Energy, the Ministry of Health \& Welfare, the Ministry of Food and Drug Safety)(Project number: 9991006766, KMDF_PR_20200901_0093).

\section{Authors' contributions}

H.K. and W.J. had full access to all the data in the study and take responsibility for the integrity of data and accuracy of data analysis. Concept and design were done by H.K. and S-I.J. Acquisition, analysis, and interpretation of data were done by H.K., S.H.K, and W.J. Drafting of the manuscript was done by H.K. Critical revision of the manuscript for important intellectual content was done by Y.K., E-C.P., and S-I.J. Statistical analysis was done by H.K., W.J., and Y.K. Psychiatric consultation was done by J.S.R, J.H.S. and J-H.S. Supervision was done by E-C.P. and S-I.J. All authors reviewed the manuscript. The author(s) read and approved the final manuscript.

\section{Funding}

This work was supported by the Korea Medical Device Development Fund grant, funded by the government of Korea (the Ministry of Science and ICT; the Ministry of Trade, Industry and Energy; the Ministry of Health \&Welfare; and the Ministry of Food and Drug Safety; Project Number: KMDF_PR_20200901_0093, 9991006766). The funding sources had no role in the design and conduct of the study; collection, management, analysis, and interpretation of the data; preparation, review, or approval of the manuscript; or the decision to submit the manuscript for publication.

\section{Availability of data and materials}

The Korean National Health Insurance Service-National Sample Cohort is a public, open-access database. It is based on the health insurance claim data of all Koreans, and the sample cohort is available for public purposes and scientific research. The authors do not have permission to share these data. The sample cohort data are available after acceptance of approval for use by the national health insurance service. (https://nhiss.nhis.or.kr/bd/ab/bdaba 000eng.do).

\section{Declarations}

\section{Ethics approval and consent to participate}

We assert that all procedures contributing to this work comply with the ethical standards of the relevant national and institutional committees on human experimentation and with the Helsinki Declaration of 1975, as revised in 2008. As the NHIS-NSC data do not contain any identifying information, the study was approved as exempt by the Institutional Review Board of Yonsei University's Health System (4-2021-0155). Since we used the de-identified these data, the need for informed consent was waived by the Institutional Review Board of Yonsei University's Health System (4-2021-0155).

\section{Consent for publication}

Not applicable.

\section{Competing interests}

The authors declare that they have no competing interests.

\section{Author details}

'Department of Preventive Medicine \& Institute of Health Services Research, Yonsei University College of Medicine, 50 Yonsei-ro, Seodaemun-gu,
Seoul 03722, Republic of Korea. ${ }^{2}$ Institute of Health Services Research, Yonsei University, Seoul, Republic of Korea. ${ }^{3}$ Institute of Behavioral Science in Medicine, Yonsei University, Seoul, Republic of Korea. ${ }^{4}$ Department of Psychiatry, Yonsei University College of Medicine, Seoul, Republic of Korea. ${ }^{5}$ Department of Public Health, Graduate School, Yonsei University, Seoul, Republic of Korea. ${ }^{6}$ Department of Hospital Administration, Graduate School of Public Health, Yonsei University, Seoul, Republic of Korea.

Received: 10 August 2021 Accepted: 4 January 2022

Published online: 14 January 2022

\section{References}

1. Härter MC, Conway KP, Merikangas KR. Associations between anxiety disorders and physical illness. Eur Arch Psychiatry Clin Neurosci. 2003;253(6):313-20.

2. van't Land H, Verdurmen J, Ten Have M, van Dorsselaer S, Beekman A, de Graaf R. The association between arthritis and psychiatric disorders; results from a longitudinal population-based study. J Psychosom Res. 2010;68(2):187-93.

3. Becker E, Orellana Rios CL, Lahmann C, Rücker G, Bauer J, Boeker M. Anxiety as a risk factor of Alzheimer's disease and vascular dementia. Br J Psychiatry. 2018;213(5):654-60.

4. Santabárbara J, Lipnicki DM, Villagrasa B, Lobo E, Lopez-Anton R. Anxiety and risk of dementia: systematic review and meta-analysis of prospective cohort studies. Maturitas. 2019;119:14-20.

5. Clarke DM, Currie KC. Depression, anxiety and their relationship with chronic diseases: a review of the epidemiology, risk and treatment evidence. Med J Aust. 2009;190:S54-60.

6. Whyte EM, Mulsant BH. Post stroke depression: epidemiology, pathophysiology, and biological treatment. Biol Psychiatry. 2002;52(3):253-64.

7. Zhang Y, Chen Y, Ma L. Depression and cardiovascular disease in elderly: current understanding. J Clin Neurosci. 2018;47:1-5.

8. Celano CM, Daunis DJ, Lokko HN, Campbell KA, Huffman JC. Anxiety disorders and cardiovascular disease. Curr Psychiatry Rep. 2016;18(11):101.

9. Reiner IC, Tibubos AN, Werner AM, Ernst M, Brähler E, Wiltink J, et al. The association of chronic anxiousness with cardiovascular disease and mortality in the community: results from the Gutenberg health study. Sci Rep. 2020;10(1):12436.

10. Barger SD, Sydeman SJ. Does generalized anxiety disorder predict coronary heart disease risk factors independently of major depressive disorder? J Affect Disord. 2005;88(1):87-91.

11. Machado S, Sancassiani F, Paes F, Rocha N, Murillo-Rodriguez E, Nardi AE. Panic disorder and cardiovascular diseases: an overview. Int Rev Psychiatry. 2017;29(5):436-44.

12. Tully PJ, Cosh SM, Baune BT. A review of the affects of worry and generalized anxiety disorder upon cardiovascular health and coronary heart disease. Psychol Health Med. 2013;18(6):627-44.

13. Brook CA, Schmidt LA. Social anxiety disorder: a review of environmental risk factors. Neuropsychiatr Dis Treat. 2008;4(1):123-43.

14. Morrison AS, Heimberg RG. Social anxiety and social anxiety disorder. Annu Rev Clin Psychol. 2013;9:249-74.

15. Asnaani A, Richey JA, Dimaite R, Hinton DE, Hofmann SG. A cross-ethnic comparison of lifetime prevalence rates of anxiety disorders. J Nerv Ment Dis. 2010;198(8):551.

16. Kessler RC, Chiu WT, Demler O, Walters EE. Prevalence, severity, and comorbidity of 12-month DSM-IV disorders in the National Comorbidity Survey Replication. Arch Gen Psychiatry. 2005;62(6):617-27.

17. Stein DJ, Lim CCW, Roest AM, de Jonge P, Aguilar-Gaxiola S, Al-Hamzawi $\mathrm{A}$, et al. The cross-national epidemiology of social anxiety disorder: data from the world mental health survey initiative. BMC Med. 2017;15(1):143.

18. Katzelnick DJ, Greist JH. Social anxiety disorder: an unrecognized problem in primary care. J Clin Psychiatry. 2001;62:11-6.

19. Lee J, Lee JS, Park S-H, Shin SA, Kim K. Cohort profile: the National Health Insurance Service-National Sample Cohort (NHIS-NSC), South Korea. Int J Epidemiol. 2016;46(2):e15

20. Parsons LS. Performing a 1: N case-control match on propensity score. In: Proceedings of the 29th Annual SAS users group international conference: SAS Institute Cary, NC; 2004. p. e11. Available at http://www2.sas. com/proceedings/sugi29/165-29.pdf. 
21. Charlson ME, Pompei P, Ales KL, MacKenzie CR. A new method of classifying prognostic comorbidity in longitudinal studies: development and validation. J Chronic Dis. 1987:40(5):373-83.

22. Sundararajan V, Henderson T, Perry C, Muggivan A, Quan H, Ghali WA. New ICD-10 version of the Charlson comorbidity index predicted inhospital mortality. J Clin Epidemiol. 2004;57(12):1288-94.

23. Watkins LL, Blumenthal JA, Davidson JR, Babyak MA, McCants CB $J$ r, Sketch MH Jr. Phobic anxiety, depression, and risk of ventricular arrhythmias in patients with coronary heart disease. Psychosom Med. 2006;68(5):651-6.

24. Tully PJ, Bennetts JS, Baker RA, McGavigan AD, Turnbull DA, Winefield HR. Anxiety, depression, and stress as risk factors for atrial fibrillation after cardiac surgery. Heart Lung. 2011:40(1):4-11.

25. HabiboviC M, Pedersen SS, van den Broek KC, Theuns DAMJ, Jordaens $L$, van der Voort PH, et al. Anxiety and risk of ventricular arrhythmias or mortality in patients with an implantable cardioverter defibrillator. Psychosom Med. 2013;75(1):36-41.

26. Stein DJ, Aguilar-Gaxiola S, Alonso J, Bruffaerts R, De Jonge P, Liu Z, et al. Associations between mental disorders and subsequent onset of hypertension. Gen Hosp Psychiatry. 2014;36(2):142-9.

27. Aronow WS. Etiology, pathophysiology, and treatment of atrial fibrillation: part 1. Cardiol Rev. 2008;16(4):181-8.

28. Aronow WS, Banach M. Atrial fibrillation: the new epidemic of the ageing world. J Atr Fibrillation. 2009;1 (6):154

29. Bajkó Z, Szekeres C-C, Kovács KR, Csapó K, Molnár S, Soltész P, et al. Anxiety, depression and autonomic nervous system dysfunction in hypertension. J Neurol Sci. 2012;317(1-2):112-6.

30. Lambert E, Dawood T, Straznicky N, Sari C, Schlaich M, Esler M, et al. Association between the sympathetic firing pattern and anxiety level in patients with the metabolic syndrome and elevated blood pressure. J Hypertens. 2010:28(3):543-50

31. Byrd JB, Powers JD, Magid DJ, Tavel HM, Schmittdiel JA, O'Connor PJ, et al. Detection and recognition of hypertension in anxious and depressed patients. J Hypertens. 2012;30(12):2293-8.

32. Furmark T, Tillfors M, Everz P, Marteinsdottir I, Gefvert O, Fredrikson M. Social phobia in the general population: prevalence and sociodemographic profile. Soc Psychiatry Psychiatr Epidemiol. 1999;34(8):416-24

33. Park E-C. Evaluating the consistency of health insurance claim disease code and medical record and improvement plan: Health Insurance Review \& Assessment Service; 2017. Available at http://www.alio.go.kr/ informationResearchView.do?seq $=2343982$

\section{Publisher's Note}

Springer Nature remains neutral with regard to jurisdictional claims in published maps and institutional affiliations.

Ready to submit your research? Choose BMC and benefit from:

- fast, convenient online submission

- thorough peer review by experienced researchers in your field

- rapid publication on acceptance

- support for research data, including large and complex data types

- gold Open Access which fosters wider collaboration and increased citations

- maximum visibility for your research: over $100 \mathrm{M}$ website views per year

At BMC, research is always in progress.

Learn more biomedcentral.com/submissions 